\title{
Attenuation of the self-renewal of transit-amplifying osteoblast progenitors in the murine bone marrow by $17 \beta$-estradiol
}

\author{
Gina B. Di Gregorio, Matsuo Yamamoto, A. Afshan Ali, Etsuko Abe, Paula Roberson, \\ Stavros C. Manolagas, and Robert L. Jilka
}

Division of Endocrinology and Metabolism and the University of Arkansas for Medical Sciences Center for Osteoporosis and Metabolic Bone Diseases, Central Arkansas Veterans Healthcare System, University of Arkansas for Medical Sciences, Little Rock, Arkansas, USA

Address correspondence to: Robert L. Jilka, Division of Endocrinology and Metabolism, Slot 587, University of Arkansas for Medical Sciences, 4301 West Markham Street, Little Rock, Arkansas 72205, USA. Phone: (501) 686-7896; Fax: (501) 686-8954; E-mail: rljilka@life.uams.edu.

Received for publication October 26, 2000, and accepted in revised form February 15, 2001.

In agreement with evidence that estrogens slow the rate of bone remodeling by suppressing the production of both osteoclasts and osteoblasts, loss of estrogens leads to an increase in the number of osteoclast as well as early osteoblast progenitors (CFU-osteoblasts; CFU-OBs) in the murine bone marrow. Here we show that $\mathrm{CFU}-\mathrm{OBs}$ are early transit-amplifying progenitors, i.e., dividing cells capable of limited self-renewal, and that $17 \beta$-estradiol acts in vivo and in vitro to attenuate their self-renewal by approximately $50 \%$. Consistent with a direct receptor-mediated action of estrogens on early mesenchymal cell progenitors, anti-estrogen receptor- $\alpha$ (anti-ER $\alpha$ ) Ab's stain a small number of marrow cells that exhibit characteristics of primitive undifferentiated cells, including a high nucleus/cytoplasm ratio and lack of lineage-specific biochemical markers; the effect of $17 \beta$-estradiol on CFU-OB self-renewal is absent in mice lacking ER $\alpha$. Because both osteoblasts and the stromal/osteoblastic cells that are required for osteoclast development are derived from CFU-OBs, suppression of the self-renewal of this common progenitor may represent a key mechanism of the anti-remodeling effects of estrogens.

J. Clin. Invest. 107:803-812 (2001).

\section{Introduction}

Estrogens attenuate the remodeling of the adult skeleton by basic multicellular units (BMUs), temporary anatomic structures comprising osteoclasts in the front and osteoblasts in the rear $(1,2)$. Conversely, loss of estrogens increases bone remodeling by several-fold (3-6).

Consistent with the temporary nature of the BMUs, it is now widely established that the rate of production and the life span of its executive cells are critical determinants of the rate of bone remodeling (7). Loss of estrogens increases osteoclast formation. This results from the removal of suppressive effects of estrogens on the production and/or action of cytokines such as IL-1, IL-6, TNF, and macrophage colony-stimulating factor (M-CSF) that govern the formation of osteoclasts from their hematopoietic precursors (7-9). These effects are exerted via the estrogen receptor and, in particular, protein-protein interaction between the receptors and other transcription factors involved in the regulation of the biosynthesis of these cytokines.

We and others have demonstrated previously that loss of estrogens in animals and humans also increases bone formation by increasing the number of osteoblasts (3-6); however, the increased bone formation is not sufficient to keep pace with the increased bone resorption. This response appears to be due to an increase in the production of early uncommitted osteoblast progeni- tors designated CFU-osteoblasts (CFU-OBs). Indeed, SAMP6 mice - a model of defective osteoblastogenesis - fail to exhibit an increase in CFU-OB, osteoblast numbers, and bone formation after loss of sex steroids $(10,11)$. Nonetheless, little is known about these progenitors or the mechanisms underlying their increase in estrogen deficiency, even though we have determined that the increase in CFU-OB after ovariectomy is not due to the release of growth factors from the bone matrix during bone resorption (6).

It has been established that in regenerating tissues such as gut, skin, lens epithelium, or the hematopoietic marrow, a change in executive cell production is accomplished by changes in the behavior of tissue-specific progenitors (12-16). These progenitors comprise stem cells and their immediate progeny - early transitamplifying cells. The defining property of both these progenitors is their ability to self-renew. Specifically, they may divide to produce two identical daughter cells (self-renewal with amplification), or one identical daughter cell and one cell with more differentiated characteristics (self-renewal without amplification), or two cells with a more differentiated phenotype $(16,17)$. The decision to self-renew or to differentiate may be stochastic or may be governed by factors in the local microenvironment. Stem cells are usually quiescent, i.e., they divide only occasionally. However, they have an 
extremely high capacity for self-renewal and thus serve as a reservoir of executive cells throughout life. On the other hand, early transit-amplifying progenitors are normally proliferating, and their self-renewal capacity lasts only for a limited number of cell divisions. Thereafter, their progeny consists solely of more differentiated precursors, which are then designated as late transitamplifying cells. Rapid increases in executive cell production can thus be achieved by stimulating the selfrenewal of early transit-amplifying progenitors.

Bone marrow contains stem cells that give rise to osteoblasts, as well as adipocytes, stromal cells, chondrocytes, and muscle cells, when maintained in the appropriate environment (18-21). Because of their ability to form colonies of fibroblastic cells when placed into culture, these progenitors have been designated CFU-fibroblasts (CFU-Fs). Be that as it may, in mice the CFU-F population is heterogeneous because only about half of CFU-F colonies contain osteoblast progenitors, as evidenced by the formation of a mineralized bone matrix either in vivo or in vitro $(22,23)$. Thus, $\mathrm{CFU}-\mathrm{OB}$, as defined above, represents the osteogenic subset of CFU-F.

In this study we demonstrate that most CFU-OBs are dividing early transit-amplifying cells and that $17 \beta$ estradiol suppresses their self-renewal via the $\alpha$ form of the estrogen receptor. Consistent with a receptor-mediated direct action of estrogens on early mesenchymal cell progenitors, we also show that a small number of undifferentiated progenitors in bone marrow cultures stain with anti-estrogen receptor- $\alpha(E R \alpha) A b$ 's and that the hormonal effect on CFU-OB self-renewal is absent in mice lacking $E R \alpha$.

\section{Methods}

Chemicals and reagents. Type I rat-tail collagen, 5-fluorouracil, $17 \beta$-estradiol, 3,3-diaminobenzidine (DAB), avidin-horseradish peroxidase (HRP), and ExtravidinFITC were from Sigma Chemical Co. (St. Louis, Missouri, USA). Phenol red-free Eagle's MEM with Hanks' salts and $\alpha M E M$ were from GIBCO BRL (Gaithersburg, Maryland, USA). FBS preselected for support of CFU-OB development was from HyClone Laboratories (Logan, Utah, USA) and was heat inactivated before use. L-ascorbate-2-phosphate (A2P) was from Wako Chemicals USA Inc. (Richmond, Virginia, USA); ICI 182,780 was from Tocris Cookson Inc. (Ballwin, Missouri, USA); and bacterial collagenase type II (204 $\mathrm{U} / \mathrm{mg}$ ) was from Worthington Biochemicals Corp. (Freehold, New Jersey, USA). Rabbit polyclonal Ab MC20 against an epitope in the $\mathrm{COOH}$-terminus of murine ER $\alpha$ was from Santa Cruz Biotechnology Inc. (Santa Cruz, California, USA). Mouse mAb ERnt against an epitope in the $\mathrm{NH}_{2}$-terminus of human $\mathrm{ER} \alpha$ was a gift from Elizabeth Allegreto (Ligand Pharmaceuticals, San Diego, California, USA) (24). The epitope is $100 \%$ homologous in human and murine ER $\alpha$. Rat anti-mouse $\mathrm{CD} 11 \mathrm{~b} \mathrm{mAb}$ was from Chemicon International (Temecula, California, USA). Biotinylated goat anti-rabbit or anti-mouse IgG Ab's and FITC-labeled goat anti-rat IgG were from Southern Biotechnology Associates Inc. (Birmingham, Alabama, USA). TSA-IHC signal amplification kit was purchased from NEN Life Science Products Inc. (Boston, Massachusetts, USA).

Animals. Swiss-Webster female mice and Hartley guinea pigs were from Harlan Bioproducts for Science Inc. Indianapolis, Indiana, USA. Ovariectomies were performed on 4-month-old mice as described previously (6), and estrogen replacement was achieved by injecting (subcutaneously) $17 \beta$-estradiol ( $20 \mathrm{ng} / \mathrm{g}$ body weight) dissolved in sesame oil. C57BL/6 mice harboring a transgene consisting of the osteocalcin gene 2 (OG2) promoter driving the expression of $\beta$-galactosidase (OG2-lacZ mice) were obtained from our breeding colony established with founders generated by Patricia Ducy and Gerard Karsenty (Baylor College of Medicine, Houston, Texas, USA) (25). Northern blot analysis indicated expression of the lacZ transgene in bone, but not in other tissues such as liver, spleen, and brain (not shown). Heterozygous knockout mice for ER $\alpha$ on a C57BL/ 6 background (26) were obtained from Ken Korach (National Institute of Environmental Health Sciences, Research Triangle Park, North Carolina, USA). Homozygous knockout animals and their wild-type littermates were generated from the heterozygote breeding pairs. The genotype of these mice was determined using PCR for the $E R \alpha$ gene and the neo gene used to generate the knockout mice. Animals were used and maintained in accordance with NIH guidelines on the care and use of laboratory animals.

Isolation of bone marrow cells and quantification of CFU-Fs and CFU-OBs. Mice were 4-6 months old at the time of marrow cell harvest. After dissection, the metaphyseal ends of femurs were removed and femurs were placed into a $1.5-\mathrm{ml}$ Eppendorf tube containing $0.5 \mathrm{ml}$ of Eagle's MEM with Hanks' salts, $100 \mathrm{U} / 1$ penicillin, 0.1 $\mathrm{mg} / \mathrm{l}$ streptomycin, and $2 \mathrm{mM}$ L-glutamine (PSG) supplemented with $15 \% \mathrm{FBS}$, and centrifuged at $11,750 \mathrm{~g}$ for 2-3 minutes at room temperature to elute marrow cells, as described previously for rat long bones (27). Cells were resuspended using a wide-bore 1 -ml serological pipette in the above medium. Debris was removed by filtration over a nylon mesh, and cell number was determined using a Coulter Counter after removal of red blood cells with Zapoglobin (Coulter Corp., Miami, Florida, USA).

The number of CFU-Fs and CFU-OBs in murine bone marrow isolates and in cultures of bone marrow cells was determined in cocultures with irradiated guinea pig marrow cells as described previously (28). Briefly, marrow cells were obtained from the femurs and tibiae of 2to 3-month-old female Hartley guinea pigs by flushing with a 22-gauge needle and resuspended in $60 \mathrm{ml}$ Eagle's MEM medium containing Hanks' salts and 15\% FBS. Cells were $\gamma$-irradiated with a $\mathrm{Co}^{57}$ source for 50 minutes at $1.2 \mathrm{~Gy} /$ minute. After rinsing by centrifugation, cells were resuspended in QMEM medium with $15 \%$ FBS, counted and cultured at $2.5 \times 10^{6}$ per $10-\mathrm{cm}^{2}$ well of a six-well plate. In some experiments, mitomycin $\mathrm{C}$ treatment was substituted for $\gamma$-irradiation. There was 
no difference between $\gamma$-irradiated cells and mitomycin $\mathrm{C}$-treated cells with respect to their ability to support CFU-F and CFU-OB development.

For assay of CFU-F and CFU-OB number in freshly isolated marrow cells, duplicate cultures were established, each containing $0.5,1.0,1.5$, or $2 \times 10^{6}$ murine marrow cells per $10-\mathrm{cm}^{2}$ well with guinea pig feeder cells in $4 \mathrm{ml}$ of $\alpha$ MEM medium, $15 \% \mathrm{FBS}$, and $1 \mathrm{mM}$ A2P. Half of the medium was replaced every 5 days. Fibroblastic colonies (CFU-F) were enumerated at 10 days of culture after staining for alkaline phosphatase, and CFU-OBs were enumerated at 25 days of culture after von Kossa staining. Osteocalcin-synthesizing cells in cultures established from OG2- $\beta$-gal mice were visualized by staining for $\beta$-galactosidase with X-gal (Amersham Pharmacia Biotech, Piscataway, New Jersey, USA) after fixation with neutral buffered formalin.

Colonies containing more than 50 fibroblastic cells were enumerated and plotted as a function of the number of cells seeded. Linear regression was used to determine the number of colonies per $10^{6}$ cells seeded. Data from wells containing fewer than five colonies were excluded from analysis to avoid the high variability of phenomena that occurs at low frequency. Data from wells containing more than 150 colonies were also excluded because of the difficulty in distinguishing overlapping colonies.

Determination of CFU-F and CFU-OB self-renewal. To assess the CFU-F and CFU-OB content of adherent fibroblastic colonies that developed after 7 days of culture, the colony was first isolated using a cloning cylinder. Nonadherent cells were removed by rinsing with PBS. Then cells were detached by incubation with $0.05 \%$ trypsin, $0.53 \mathrm{mM}$ EDTA, and $400 \mathrm{U} / \mathrm{ml}$ bacterial collagenase type II in PBS for 30 minutes at $37^{\circ} \mathrm{C}$. Detached cells were transferred to a tube containing $100 \%$ FBS, rinsed, and aliquots placed into separate cultures for the determination of CFU-Fs and CFU-OBs, as described above. Results of preliminary experiments not shown here revealed that guinea pig feeder cells were required for colony development in secondary cultures.

Self-renewal was quantified using marrow cells precultured in type I collagen gels. Rat-tail type I collagen $(3 \mathrm{mg} / \mathrm{ml}$ in $0.1 \%$ acetic acid) was mixed with an equal volume of $2 \times \alpha \mathrm{MEM}$ with PSG, $30 \% \mathrm{FBS}$, and $0.005 \mathrm{~N}$ $\mathrm{NaOH}$. Then, freshly isolated marrow cells were added to yield a final concentration of $5-10 \times 10^{6}$ cells per milliliter of collagen gel and pipetted into $10-\mathrm{cm}^{2}(1.0-1.5 \mathrm{ml})$ or $5-\mathrm{cm}^{2}(1.0 \mathrm{ml})$ wells $(29)$. Gels were allowed to form at $37^{\circ} \mathrm{C}$ for 2 hours. The gel was detached from the plasticware and overlaid with $1.5-2.5 \mathrm{ml}$ of $\alpha \mathrm{MEM}$ supplemented with $15 \%$ FBS. One half of the medium was replaced every 5 days. Preliminary experiments established that more than $95 \%$ of cells were incorporated into the gel, but total cell number declined during the first 5 days, mainly due to loss of nonadherent hematopoietic cells that failed to attach to the collagenous matrix. No CFU-Fs or CFU-OBs were lost from the gel. To determine CFU-F and CFU-OB number in the gel, cells were released by incubation with $400 \mathrm{U} / \mathrm{ml}$ bacterial collagenase type II in PBS for approximately 30 minutes at $37^{\circ} \mathrm{C}$. After resuspension and counting, the number of CFU-Fs and CFU-OBs was determined as described above after seeding at $2.5,5.0,10,20$, or $40 \times 10^{3}$ cells per $10-\mathrm{cm}^{2}$ well.

Immunocytochemistry. Marrow cell cultures were established at $0.7 \times 10^{6} / \mathrm{cm}^{2}$ on collagen type I-coated glass slides (Becton Dickinson Labware, Bedford, Massachusetts, USA) and maintained for 5-6 days in $\alpha$ MEM supplemented with $15 \%$ FBS and $1 \mathrm{mM} \mathrm{A2P}$. Cells were fixed in $4 \%$ formaldehyde in PEM (80 mM PIPES, 5 mM EGTA, 2 mM MgCl $2, \mathrm{pH}$ 6.8) for 30 minutes at $4^{\circ} \mathrm{C}$. Subsequent procedures were done at room temperature. Samples were quenched in $1 \mathrm{mg} / \mathrm{ml} \mathrm{NaBH}_{4}$ in PEM for 20 minutes, permeabilized for 30 minutes in $0.5 \%$ Triton X-100 in PEM, and then blocked for 1 hour in $5 \%$ dry milk in TBST $(20 \mathrm{mM}$ Tris- $\mathrm{HCl}, 150$ $\mathrm{mM} \mathrm{NaCl}, 0.1 \%$ Tween $20, \mathrm{pH}$ 7.4) (30). Slides were then incubated for 2 hours with either mouse $\mathrm{mAb}$ ERnt $(4 \mu \mathrm{g} / \mathrm{ml})$ or with MC-20 polyclonal $\mathrm{Ab}(1 \mu \mathrm{g} / \mathrm{ml})$ in TBST. After extensive rinsing, the slides were incubated with biotinylated anti-mouse or anti-rabbit second $\mathrm{Ab}(1: 600)$ for 1 hour. Biotinylated Ab's were visualized using HRP-conjugated Extravidin and DAB substrate. A tyramide signal amplification kit was used to enhance peroxidase staining. Where indicated, alkaline phosphatase staining was done with kit number 86R (Sigma Chemical Co.) after staining for ER $\alpha$, which was detected with FITC-labeled goat anti-rabbit Ab. Macrophages were detected by staining for 2 hours with rat anti-mouse CD11b Ab (1:50), followed by 1-hour incubation with FITC-labeled goat anti-rat Ab, after immunoperoxidase staining for $\mathrm{ER} \alpha$.

Statistics. After establishing that data were homogeneous in variance and normally distributed, they were analyzed by $t$ test or a mixed effects ANOVA model, as appropriate. The mixed-effects model was used for determining SE estimates of CFU-F and CFU-OB number in serial dilution assays. This model used a first-order autoregressive covariance structure to test for treatment effects (31). Significant differences among treatments and vehicle were determined using model estimates of slopes and SEs to derive $t$ tests.

\section{Results}

Proliferative and self-renewal properties of murine CFU-Fs and CFU-OBs. The proliferative status of CFU-Fs and CFU-OBs was assessed in vivo by administering 5 -fluorouracil (5-FU; $150 \mu \mathrm{g} / \mathrm{g}$ body weight) to 4-month-old Swiss-Webster mice. Femoral marrow cells were obtained for determination of CFU-F and CFU-OB number 5 days later. The number of CFU-Fs and CFU-OBs in the femurs of animals receiving 5-FU was significantly reduced compared with that of animals injected with vehicle (Table 1). However, when expressed per $10^{6}$ marrow cells, there was no appreciable change due to the coincident reduction in total number of marrow cells in the isolate. In three separate experiments we found that mice injected with 5-FU had only $29 \% \pm 8 \%$ 
Table 1

Inhibition of CFU-F and CFU-OB production in vivo by 5-FU

\begin{tabular}{lcccc} 
& \multicolumn{2}{c}{ CFU-F } & \multicolumn{2}{c}{ CFU-OB } \\
Animal & perfemur & $\begin{array}{c}\text { per } 10^{6} \\
\text { marrow cells }\end{array}$ & per femur & $\begin{array}{c}\text { per } 10^{6} \\
\text { treatment }\end{array}$ \\
Vehicle & $2307 \pm 422$ & $203 \pm 23$ & $1387 \pm 201$ & $123 \pm 9$ \\
5-FU & $344 \pm 209^{\mathrm{A}}$ & $440 \pm 180$ & $168 \pm 143^{\mathrm{A}}$ & $145 \pm 110$
\end{tabular}

Mice were given 5-FU or vehicle by tail-vein injection as described in Methods ( $n=4-5$ per group). Five days later, marrow cells were obtained from femurs for the determination of CFU-Fs and CFU-OBs. Cells from individual animals were analyzed separately. Average marrow cell yield was $11 \pm 1.0 \times 10^{6}$ cells per femur for vehicle-treated animals and $0.5 \pm 0.2 \times 10^{6}$ cells per femur for 5 -FU-treated animals. Data shown represent the mean $( \pm$ SEM) number of progenitors. ${ }^{A} P<0.01$ versus vehicle. Identical results were obtained in a second experiment using cells isolated 3 days after administration of 5-FU.

(SEM) of CFU-F progenitors and $15 \% \pm 4 \%$ of CFU-OBs, as compared with mice receiving vehicle, indicating that the majority of CFU-Fs and CFU-OBs in adult mice are undergoing cell division.

We next performed in vitro studies to establish whether CFU-Fs and CFU-OBs are capable of selfrenewal - i.e., whether they produce identical daughter CFU-F and CFU-OB progenitors. Bone marrow cells were cultured for 7 days to allow formation of colonies of fibroblastic cells from the progenitors present in the marrow isolate. Then, cells from each of 12 randomly selected colonies were enzymatically dispersed using cloning cylinders, and secondary cultures were established to determine the number of CFU-F and CFU-OB progenitors present within each colony. Each colony contained numerous CFU-F progenitors, ranging in number from 12 to 296 (Figure 1a); however, only 5 of the 12 colonies contained CFU-OBs, ranging in number between 24 to 144 (Figure 1b). Interestingly, the ratio of CFU-OBs to CFU-Fs within each colony was highly variable (0.1-0.8), and CFU-OBs were never greater than CFU-Fs. Additional experiments $(n=4)$ to determine the prevalence of progenitors among all adherent cells in 5- to 6-day marrow cell cultures indicated that $1.6 \pm 0.3 \%$ were CFU-Fs and $0.8 \pm 0.2 \%$ were $C F U-O B s$.

The quantification of CFU-F and CFU-OB production in whole bone marrow cultures was optimized by culturing freshly isolated bone marrow cells within three-dimensional type I collagen gels instead of on tissue culture plasticware. Culture of marrow cells in this kind of environment has been shown to facilitate longterm viability and hematopoietic activity $(32,33)$. Moreover, cells precultured within collagen gels were easily dispersed with bacterial collagenase to establish secondary cultures for subsequent assay of CFU-Fs and CFU-OBs. As shown in Figure 2a, CFU-F and CFU-OB number increased exponentially during the first 7 days of culture of isolated marrow cells within the collagen gel. This increase was inhibited by addition of 5-FU (Figure 2b), indicating that proliferation was required for self-renewal to occur. After 16 days of culture, CFU-OB number was reduced fourfold from its value at 7 or 11 days, but CFU-Fs were unchanged.
If the increase in CFU-Fs and CFU-OBs during culture truly is due to self-renewal, the behavior of the newly generated daughter cells should be identical to that of the parental cell obtained in the bone marrow isolate. To determine whether this is indeed the case, we compared the characteristics of colonies formed by marrow-derived and in vitro-generated progenitors. Figure 3 shows that alkaline phosphatase staining of CFU-F colonies and von Kossa staining of CFU-OB colonies were indistinguishable, regardless of whether they were formed from freshly isolated marrow progenitors or from in vitro-generated progenitors. Estimates of colony size using a calibrated eyepiece reticle on a dissecting microscope indicated that the majority of colonies (both CFU-F and CFU-OB) ranged from 200 and $400 \mu \mathrm{m}$ in diameter, regardless of whether the progenitors were obtained from the bone marrow or generated in vitro (data not shown).

Next, the rate of osteoblast differentiation within the colonies was examined using marrow cells from OG2-lacZ mice (Figure 4). These mice harbor a transgene expressing $\beta$-galactosidase under the control of the OG2 osteocalcin promoter, which is activated only at the later stages of osteoblast differentiation $(25,34$, $35)$. Staining of colonies with X-gal showed that von Kossa-positive CFU-OB colonies contained blue X-
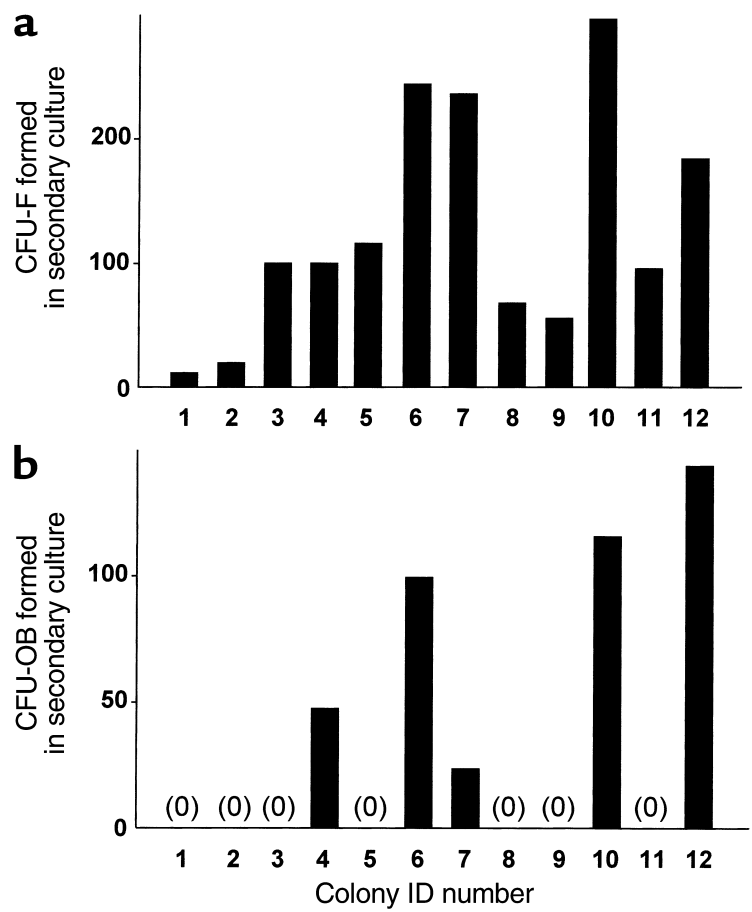

\section{Figure 1}

Content of (a) CFU-Fs and (b) CFU-OBs in fibroblastic colonies present in cultures of murine bone marrow cells. Cells were enzymatically dispersed from each of 12 randomly selected fibroblastic colonies (containing greater than 50 cells) that developed in 7-day cultures of femoral marrow cells and assayed for CFU-Fs and CFU-OBs as described in Methods. Bars represent the number of CFU-F or CFU-OB colonies obtained in the secondary culture divided by the fraction of cells used to establish the secondary culture. " 0 " indicates no colonies detected. 
Figure 2

Time kinetics of CFU-F and CFU-OB production by murine bone marrow cells cultured in type I collagen gels. (a) Marrow cell cultures were established in type I collagen gels $\left(10 \times 10^{6}\right.$ cells per gel), and CFU-F and CFU-OB content was assessed either immediately (day 0 ) or after culture for 2, 7, 11, or 16 days. The data shown represent the mean ( \pm SEM) number of CFU-Fs and CFU-OBs per gel. Preliminary experiments established that the number of CFU-Fs and CFU-OBs in the initial marrow isolate not put into the gel was indistinguishable from the 0 time values (not shown). Error bars are not visible because the symbols are larger than the error bars. Data were analyzed using mixed-effect ANOVA as described in Methods. Significant $(P<0.01)$ increases in progenitor number versus day 0 were detected at all time points, except for CFU-OBs at day 2. CFU-OB number at day 16 was significantly less than at day $11(P<0.05)$. (b) Marrow cell cultures were established in type I collagen gels as in a without (vehicle) or with $5 \mu \mathrm{g} / \mathrm{ml} 5$-FU. Progenitor number was then determined after 2 or 5 days of culture. The number of progenitors in the initial isolate (day 0 ) is expressed per $10 \times 10^{6}$ marrow cells. ${ }^{A} P<0.05$ treatment versus vehicle.

gal-stained cells (Figure 4a), demonstrating the presence of osteoblastic cells with active OG2 promoter. As shown in Figure 4b, the development of fibroblastic colonies occurred over the same period from marrowderived or in vitro-generated progenitors. More important, the time at which blue cells - representing osteoblastic cells with active OG2 promoter - appeared within these colonies was practically identical for marrow-derived and in vitro-derived progenitors. Thus, in both sets of cultures, no $\beta$-galactosidase-positive cells were observed at 2, 5, and 10 days of culture, but by 15 days a few such cells appeared. Thereafter, the number of colonies containing $\beta$-galactosidase-positive cells increased. This was followed by the mineral deposition within these colonies, as evidenced by von Kossa staining at 25 days of culture.

These findings indicate that the new CFU-OBs generated in vitro are at a similar if not identical stage of differentiation as the parental cell obtained from the bone
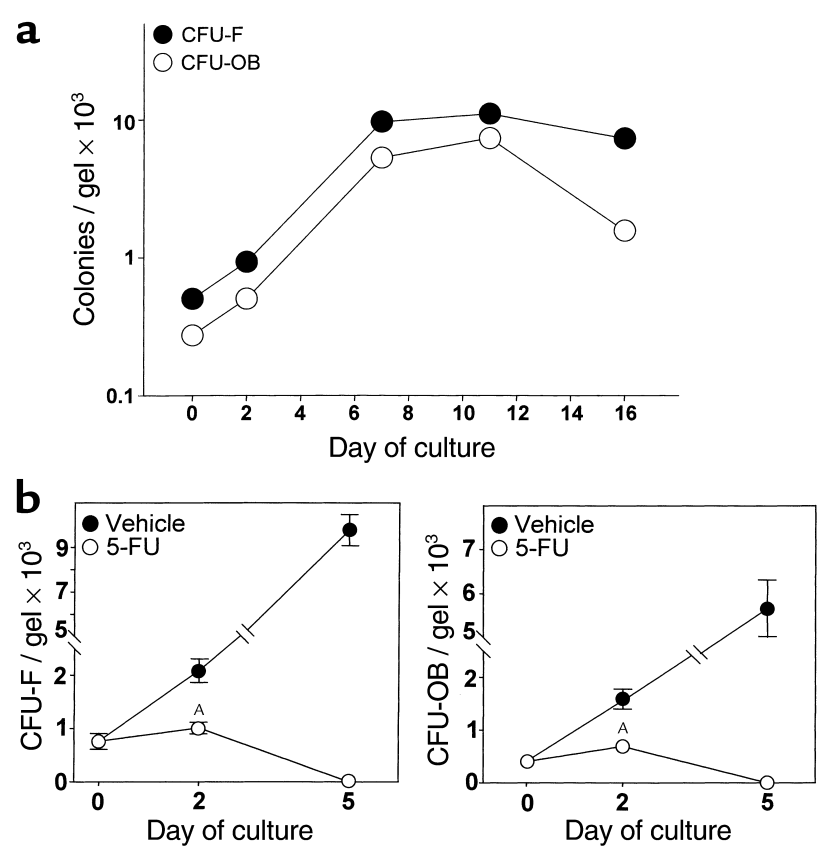

marrow and that CFU-OBs are capable of both limited self-renewal and differentiation. These are the characteristics of early transit-amplifying cells (16). Because we did not analyze differentiation markers of other cell types, however, we do not know whether the same is true for the subpopulation of CFU-Fs that do not differentiate into osteoblasts. Therefore, subsequent studies were restricted to the investigation of CFU-OB behavior.

$17 \beta$-estradiol suppresses CFU-OB self-renewal. In view of the finding that CFU-OBs are proliferating self-renewing progenitors, the increase in their number after ovariectomy that we detected in our earlier studies (6) could be due to removal of a suppressive effect of estrogens on self-renewal. To investigate whether this is the case, in the present report we added $17 \beta$-estradiol to bone marrow cells cultured in collagen gels and deter-

\section{Figure 3}

Colonies formed from freshly isolated bone marrow progenitors and from progenitors generated in vitro are morphologically indistinguishable. (a) Colonies formed from freshly isolated bone marrow cells. (b) Colonies formed from marrow cells cultured for 5 days in a collagen gel. The left panel of each section shows a $10-\mathrm{cm}^{2}$ well containing CFU-Fs stained for alkaline phosphatase (top portion) or CFUOBs stained with von Kossa to detect mineral (bottom portion). The right panel of each section shows a photomicrograph $(\times 2)$ of a typical alkaline phosphatase-positive CFU-F colony (top portion) and a von Kossa-stained CFU-OB colony (bottom portion).

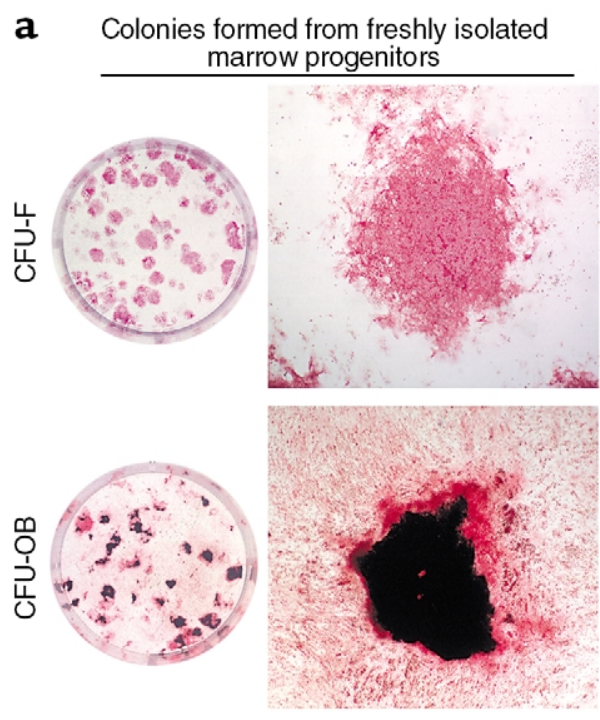

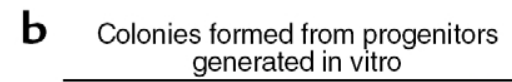

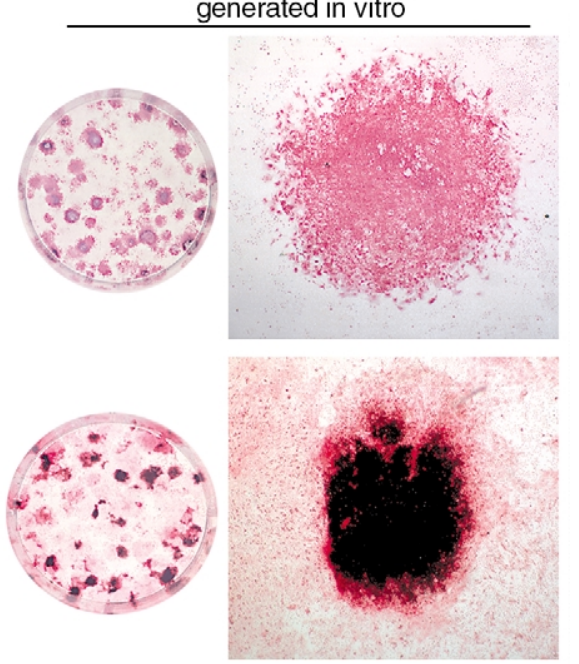




\section{Figure 4}

The time kinetics of colony development and osteoblast differentiation from freshly isolated bone marrow progenitors and from progenitors generated in vitro are identical. (a) Colony histology. Photomicrographs show colonies with a mineralized von Kossa-stained matrix and X-gal-stained blue cells (left panel, $\times 2$; right panel, $\times 10)$. Arrows indicate selected X-gal-stained blue cells that are osteoblastic as evidenced by the active OG2 promoter. (b) Kinetics of colony development. Femoral marrow cells were isolated from OG2-lac Z mice and either maintained in culture for 2,5 , $10,15,20$, or 25 days (left panel) or cultured in type I collagen gels for 6 days and then enzymatically released and cultured for the same period as the freshly isolated cells (right panel). At each time point, cultures were stained with $X$-gal to detect $\beta$-galactosidase-positive cells and according to von Kossa to detect mineral. Colonies comprising at least 50 cells were scored as fibroblastic, $\beta$-galactosidase-positive (at least 10 blue cells), or von Kossa-positive. The data shown represent the mean number $( \pm S D)$ of each type of colony per $10^{6}$ cells seeded ( $n=3$ per group). Error bars are not visible days 2 and 5 , because the symbol is larger than the error bar. Essentially identical results were obtained in a second experiment.

mined the number of CFU-OBs after 5 days of treatment. Whereas CFU-OBs increased 19 -fold in cultures incubated with vehicle, cultures incubated with as little as $1 \mathrm{nM} 17 \beta$-estradiol exhibited only 10 - to 12 -fold increase (Figure 5). In six separate experiments, $10 \mathrm{nM}$ $17 \beta$-estradiol inhibited the self-renewal of CFU-OBs by an average of $53 \% \pm 7 \%$ (SEM).

We also examined the effect of $17 \beta$-estradiol on $\mathrm{CFU}-\mathrm{OB}$ number in vivo. In this experiment, mice were ovariectomized and given $17 \beta$-estradiol $(20 \mathrm{ng} / \mathrm{g}$ body weight) or vehicle at 16 and 18 days after the operation. This time was chosen for analysis because of evidence that $\mathrm{CFU}-\mathrm{OBs}$ are increased in ovariectomized mice as early as 14 days after the operation (6). On the 20th day after the operation ( 4 days after initiation of $17 \beta$-estradiol treatment), femoral marrow cells were obtained and pooled (six mice per group), and the number of CFU-OBs was determined in triplicate cultures. The number of CFU-OBs in marrow of mice receiving $17 \beta$-estradiol was approximately $50 \%$ of that seen in mice receiving vehicle $\left(41 \pm 9\right.$ SD versus $80 \pm 15$ per $10^{6}$ marrow cells, respectively; $P<0.01$ by Student's $t$ test).

\section{Figure 5}

$17 \beta$-estradiol attenuates the self-renewal of CFU-OBs. Duplicate cultures of marrow cells in collagen gels $\left(5 \times 10^{6}\right.$ per gel) were maintained in the absence (Veh) or presence of $10^{-11}$ to $10^{-8} \mathrm{M} 17 \beta$-estradiol (E2) for 6 days and then assayed for CFU-OB content. Assay of freshly isolated marrow cells indicated that there were $90 \pm 14$ CFUOBs per $5 \times 10^{6}$ cells used to establish each culture. Thus, there was a 19.2-fold increase in CFU-OBs in cultures maintained in vehicle. The data shown represent the mean $\left( \pm\right.$ SEM) of CFU-OBs. ${ }^{A} P<0.05$ treatment versus vehicle using mixed-effects ANOVA model. Linear contrast testing indicated a significant $(P<0.05)$ dose-dependent effect.
The role of the ER in the inhibitory effect of $17 \beta$-estradiol on CFU-OB self-renewal was examined next. Consistent with a receptor-mediated action, the pure ER antagonist ICI 182,780 (50 $\mathrm{nM})$ blunted the suppressive effect of $1 \mathrm{nM} 17 \beta$-estradiol on CFU-OB self-renewal (Figure 6a). Moreover, whereas $10 \mathrm{nM} 17 \beta$-estradiol inhibited CFU-OB production in cultures from $E R \alpha^{+/+}$ mice by $61 \pm 18 \%$, it failed to suppress CFU-OB production when added to marrow cultures established from $E R \alpha^{-1}$ mice (Figure $6 \mathrm{~b}$ ). CFU-OBs from $E R \alpha^{-1-}$ mice were indistinguishable from that of $E R \alpha^{+/+}$mice with respect to colony size and von Kossa staining (not shown). These findings indicate that the $\alpha$ isoform of the ER mediates the suppressive effect of estrogen.

Expression of ER $\alpha$ in murine bone marrow cells. In view of the finding that $17 \beta$-estradiol suppressed CFU-OB selfrenewal in an ER $\alpha$-dependent fashion, immunocytochemical studies were performed to demonstrate the $E R \alpha$ protein in cells present in colonies of fibroblastic cells. Two Ab's, MC-20 and ERnt, which recognize epitopes in the $\mathrm{COOH}$-terminal (36) and $\mathrm{NH}_{2}$-terminal (24) portions of murine ER $\alpha$, respectively, were used. The 


\section{Figure 6}

The role of the ER in the suppressive effect of $17 \beta$-estradiol on CFU-OB self-renewal. (a) ICl 182,780 blocks the effect of $17 \beta$-estradiol. Marrow cell cultures were established in collagen gels $\left(7.5 \times 10^{6}\right.$ per gel $)$ in the absence or presence of $50 \mathrm{nM} \mathrm{ICl}$ 182,780. The cultures were maintained for 6 days without (Veh) or with $1 \mathrm{nM}$ $17 \beta$-estradiol and then assayed for CFU-OB number. Assay of freshly isolated cells indicated that there were $281 \pm 17$ CFU-OBs per $7.5 \times 10^{6}$ cells used to establish each culture. Thus, there was a 5.4-fold increase in $\mathrm{CFU}-\mathrm{OBs}$ in cultures maintained in vehicle in the absence of $\mathrm{ICl} 182,780$. Bars represent the mean number ( \pm SEM) of CFU-OBs per gel. ${ }^{A} P<0.05$ treatment versus vehicle as determined by mixed-effects ANOVA. (b) Lack of effect of $17 \beta$-estradiol on CFU-OBs from $E R \alpha^{-1-}$ mice. Marrow cells were obtained from $E R \alpha^{+/+}$or $E R \alpha^{-/}$mice, and collagen gel cultures were established using $8 \times 10^{6}$ cells per gel. Cultures were maintained in the absence or presence of $10 \mathrm{nM}$ $17 \beta$-estradiol for 5 days and then assayed for CFU-OBs. Assay of freshly isolated cells from $E R \alpha^{+/+}$or $E R \alpha^{-1-}$ mice indicated that there were $248 \pm 56$ or $384 \pm 56 \mathrm{CFU}-\mathrm{OBs}$, respectively, per $8 \times 10^{6}$ cells used to establish each culture. Thus, there was a 7.3-fold $\left(E R \alpha^{+/+}\right)$or 6.5 -fold $\left(E R \alpha^{-/}\right)$increase in CFU-OBs in cultures maintained in vehicle. Bars represent the mean number ( \pm SEM) of progenitors. ${ }^{A} P<0.05$ treatment versus vehicle as determined by mixed-effects ANOVA.

colonies that form in 5- to 6-day cultures comprise large cells with fibroblast-like morphology, as well as small $(5-10 \mu \mathrm{m})$ round cells with a high nucleus/cytoplasm ratio (Figure 7a). Occasionally the latter were on top of fibroblastic cells. Both anti-ER $\alpha$ Ab's predominantly stained these small cells, and the staining was seen in both the nucleus and the cytoplasm (Figure 7b). In three separate bone marrow preparations, an average of 2-3\% of the cells exhibited staining for $E R \alpha$ with either $A b$. Large fibroblastic cells stained weakly if at all, and no staining was seen with the nonimmune control IgG. Cytoplasmic and nuclear ER $\alpha$ immunoreactivity was also observed in MCF-7 breast cancer cells, used here as a positive control (Figure $7 c$, top panels), whereas neither $\mathrm{Ab}$ stained HeLa cells (Figure 7c, bottom panels), which lack ER (30). The majority of the cells staining positively with the MC-20 Ab did not express alkaline phosphatase, a marker of mesenchymal/osteoblastic cells (Figure 7d). Instead, this enzyme was observed almost exclusively in large fibroblastic cells, most of which lacked ER $\alpha$ immunostaining. MC-20 staining was also absent from cells of the monocyte/macrophage lineage, detected with anti-CD11b Ab (Figure 7e).

\section{Discussion}

Estrogen deficiency induces an increase in bone remodeling that is inappropriate relative to the need for skeletal repair $(1,3-6,37)$. This phenomenon has been documented at the tissue level by increased activation frequency, a measure that reflects the birth of new BMUs, or prolongation of the life span of existing ones (38). At the cellular level, studies in rodents $(6,39)$ and baboons (J. Owens, Genetics Institute, Andover, Massachusetts, USA; personal communication) have demonstrated that loss of estrogens is accompanied by an increase in the number of osteoclast and osteoblast progenitors. The former is evidently due to loss of suppressive effects of estrogens on the production of osteoclastogenic cytokines (7-9) and perhaps an increase in the number or activity of
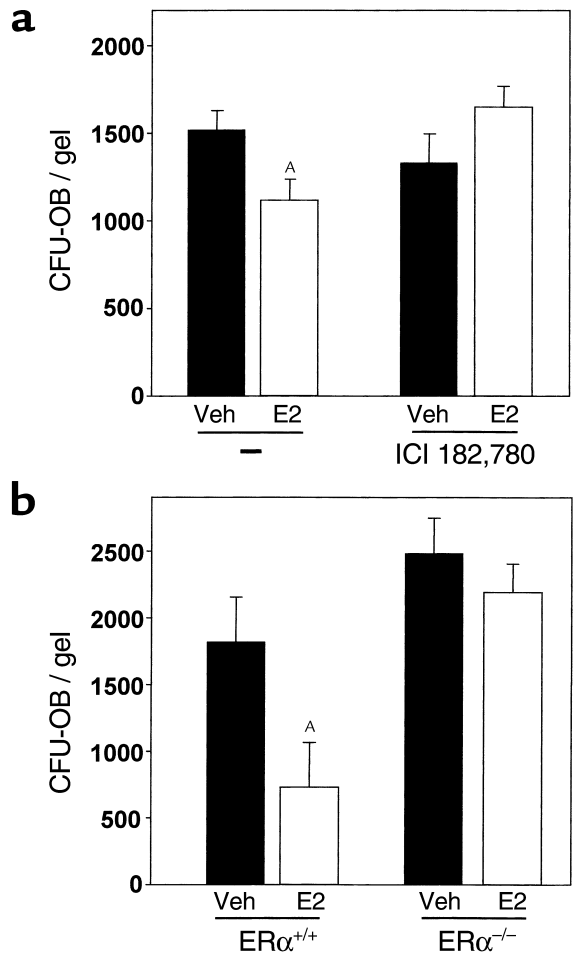

the stromal/osteoblastic cells that support osteoclast formation $(8,10,11)$. However, the mechanism underlying the increased osteoblastogenesis, as reflected by CFU-OB number, had remained unknown.

Based on evidence that CFU-OBs are present in the marrow of mice treated with 5-FU, it was thought that they represent "quiescent" mesenchymal stem cells (40). However, in these earlier studies, CFU-OB number was not quantified on a per femur basis. In this study we present evidence that 5-FU does indeed cause a severe reduction in CFU-OBs, demonstrating that about 85\% are in fact dividing in vivo. Moreover, we provide in vitro evidence that newly generated CFU-OBs are identical to the parental cell. These two lines of evidence establish that CFU-OBs undergo self-renewal. However, in agreement with previous observations of rat CFU-OBs (41), the phenomenon is limited to only a few cycles of cell division. These proliferative and self-renewal capacities of CFU-OBs define them as early transit-amplifying progenitors, analogous to progenitors found in other regenerating tissues, such as intestinal and corneal epithelium and the hair follicle, in which increased selfrenewal of a transit-amplifying progenitor provides additional mature cells when needed $(42,43)$.

Our observation that $17 \beta$-estradiol acts to suppress the production of CFU-OBs both in vitro and in vivo indicates that the increased osteoblastogenesis caused by estrogen deficiency results from the removal of this inhibitory control. Interestingly, a similar inhibitory effect of estrogens has been documented previously in the case of self-renewing transit-amplifying progenitors that give rise to cells of the inner root sheath and the mature hair fiber $(14,44)$. 

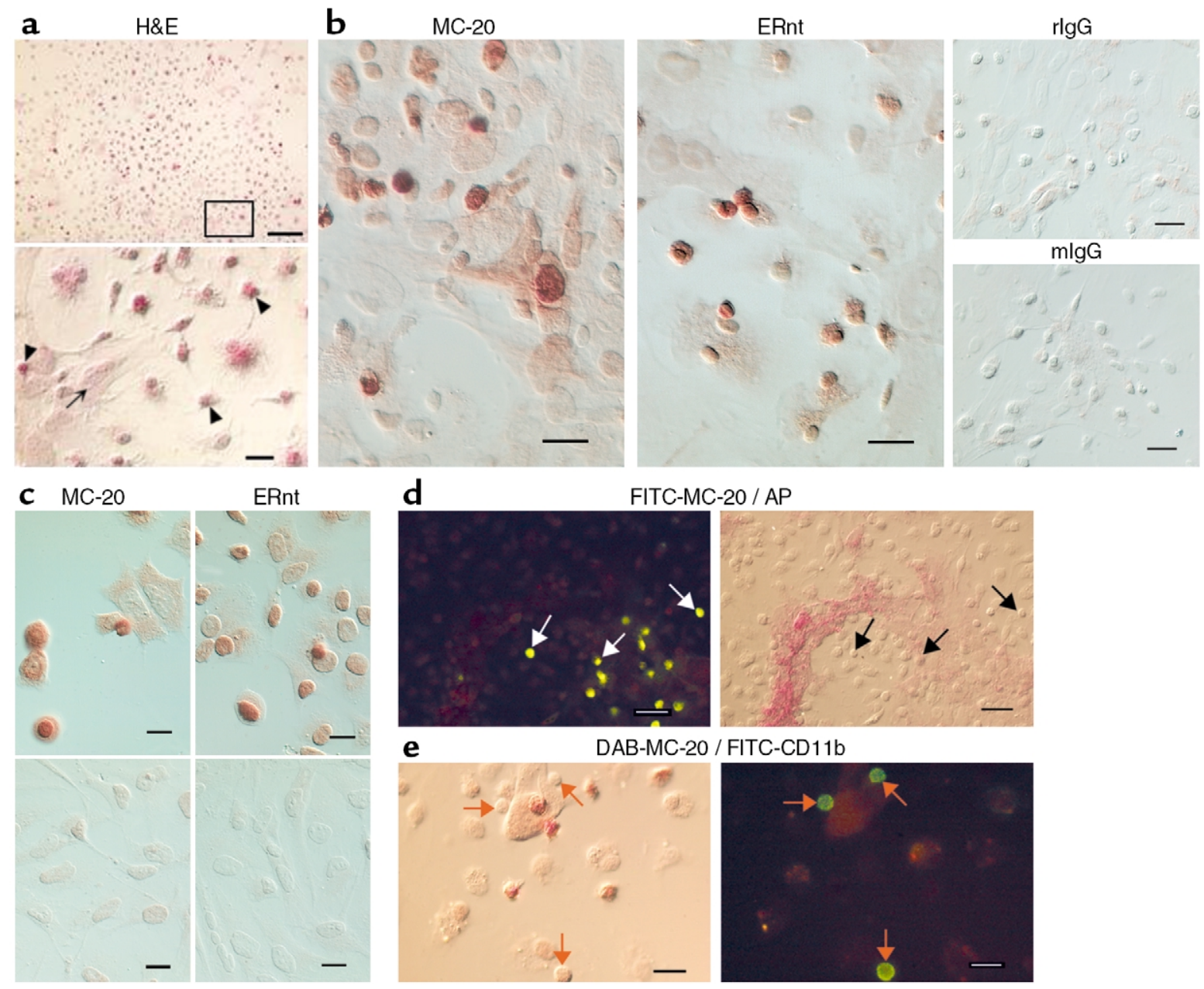

\section{Figure 7}

Immunocytochemical detection of ER $\alpha$ in cultured murine bone marrow cells. (a) Hematoxylin and eosin (H\&E) staining of a fibroblastic colony. The top panel shows a low-power view; bar, $120 \mu \mathrm{m}$. The box in the top panel indicates the area shown at high power in the bottom panel; bar, $15 \mu \mathrm{m}$. The colonies comprise fibroblast-like cells (arrow) as well as small round cells with high nucleus/cytoplasm ratio (arrowheads). (b) Immunoperoxidase staining (reddish brown) of bone marrow cells with MC-20 or ERnt anti-ER $\alpha$ Ab. Cells incubated with nonimmune rabbit ( $\mathrm{rlgG}$ ) or mouse $\operatorname{lgG}(\mathrm{mlgG}$ ) instead of anti-ER $\alpha$ Ab exhibited no staining. (c) Immunoperoxidase staining of MCF-7 cells (top panels) or HeLa cells (bottom panels) with MC-20 or ERnt Ab. (d) Photomicrographs of the same field taken with fluorescence illumination to visualize ER $\alpha$-positive cells stained with MC-20 and FITC-labeled anti-rabbit Ab (left panel) and bright-field illumination to visualize alkaline phosphatase-positive (AP-positive) cells (right panel). Arrows indicate position of ER $\alpha$-positive cells. (e) Photomicrographs of the same field taken with bright-field illumination to visualize ER $\alpha$-positive cells after immunoperoxidase staining with $\mathrm{MC}$ - 20 as in $\mathbf{b}$ (reddish brown, left panel) and fluorescence illumination to visualize CD11b-positive macrophages detected with FITC (right panel). Arrows indicate position of CD11b-positive cells. b-e: bars, $15 \mu \mathrm{m}$.

Decreased CFU-OB self-renewal could result from a direct action of estrogens on this progenitor or indirectly via the regulation of one or more factors produced by other cell(s) in the bone marrow. The former scenario is supported strongly by our immunocytochemical studies demonstrating that $E R \alpha$ is expressed in a small population of primitive and undifferentiated cells exhibiting high nucleus/cytoplasm ratio and lack of lineage-specific markers. This population represented $2-3 \%$ of all cells present in the cultures. Our contention that at least a fraction of the ER $\alpha$-positive cells are indeed CFU-OB progenitors is supported by the fact that CFU-OBs also comprise approximately $1 \%$ of the total adherent marrow cell population.
The ER $\alpha$ immunostaining in the bone marrow cells, as well as in the MCF-7 cells used as positive controls in our studies, was not always confined to the nucleus, as several cells exhibited cytoplasmic staining as well. Cytoplasmic as well as nuclear ER immunostaining within the same cell has been observed in rat mammary gland epithelial and stromal cells (36) and in cultured hippocampal neurons (45). However, in other reports ER immunostaining was observed exclusively in the nucleus $(30,46,47)$. In studies reported elsewhere, we have elucidated nongenotropic antiapoptotic signaling through the ER in cells of the osteoblastic lineage, which results from activation of a Src/Shc/ERK-signaling pathway (48). Strikingly, this activity was eliminated by nuclear, but not by membrane, targeting of the 


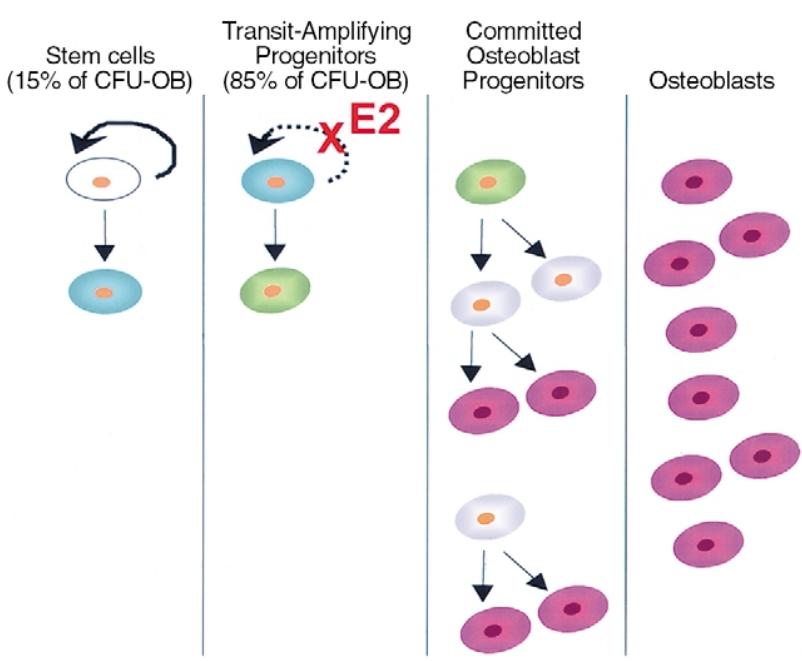

Figure 8

Regulation of osteoblast formation by estrogens. Mesenchymal stem cells (white) with high self-renewal capacity (solid arrow) give rise to early transit-amplifying osteoblast progenitors (blue) with limited selfrenewal capacity (dashed arrow). The latter differentiate into late transit-amplifying progenitors lacking self-renewal capability (green). Subsequently, late transit-amplifying cells develop into committed osteoblast progenitors (gray) that eventually give rise to fully differentiated osteoblasts (magenta). Estrogens (E2) suppress the self-renewal of early transit-amplifying progenitors. See text for additional details.

receptor protein. Moreover, it was localized within the ligand-binding domain of the ER $\alpha$ and could be dissociated from its transcriptional activity with ER peptide antagonists as well as synthetic ligands. These findings support the notion that cytoplasmic ER staining may indeed represent a biologically relevant fraction of the receptor that mediates effects outside the transcriptional activity of the protein in the nucleus. This notion has received strong support by other recent demonstrations of biologic effects of the nuclear orphan receptor TR3 and the ER, which were independent of their transcriptional activity in the nucleus $(49,50)$.

Suppression of CFU-OB production by $17 \beta$-estradiol could be due to inhibition of replication and/or a switch from symmetric (production of two identical CFU-OB daughter cells) to asymmetric replication, during which the parental cell gives rise to one identical daughter and one differentiated daughter incapable of serving as a colony-forming progenitor. Our studies do not allow us to distinguish among these possibilities. However, the fact that the $\mathrm{CFU}-\mathrm{OB}$ population expands logarithmically in vitro implies that a change in CFU-OB number is determined primarily through changes in symmetric replication, i.e., self-renewal with amplification $(16,17)$. By extension, changes in the circulating levels of estrogens might alter osteoblast number by acting on a compartment of CFU-OBs undergoing symmetric replication. Reduction of CFU-OB production by estrogens could also result from stimulation of CFU-OB apoptosis, but this possibility seems unlikely in view of the evidence that estrogens exert anti- apoptotic, as opposed to proapoptotic, effects on cells of the osteoblastic lineage (48).

Based on the above considerations, we propose a model of the regulation of osteoblast formation by estrogens in which the early transit-amplifying compartment of $\mathrm{CFU}-\mathrm{OBs}$ is the principal target of action (Figure 8). According to this model, osteoblast progenitors comprise mesenchymal stem cells and CFU-OB transit-amplifying cells, which can both self-renew and differentiate, as well as committed osteoblast precursors, which only give rise to more differentiated cells as they divide. In the latter, proliferative capacity declines with increased differentiation, with the eventual formation of the nondividing mature osteoblast. The logarithmic nature of self-renewal, combined with expansion of the committed osteoblast precursor pool during subsequent differentiation, would ensure that even a small increase in CFU-OB self-renewal after loss of estrogens would lead to a large increase in the number of osteoblasts available to the BMU. We cannot eliminate the possibility that estrogens exert a similar effect on mesenchymal stem cells. However, our observations indicate that only $15 \%$ of the total CFU-OB population are quiescent stem cells. Thus, even if estrogen deficiency increases the frequency of mesenchymal stem cell replication, it is unlikely that such an effect would substantially contribute to increased CFU-OB number.

The suppression of transit-amplifying CFU-OB selfrenewal by estrogens may be of relevance to the effects of these hormones on osteoclastogenesis because the stromal/osteoblastic cells that support osteoclast development are derived from early mesenchymal progenitors $(51,52)$. Thus, the regulation of CFU-OB selfrenewal by estrogens may be of relevance to the effects of these hormones on osteoclastogenesis, as well. We have reported previously that in SAMP6 mice, which have decreased CFU-OB number, ovariectomy failed to increase osteoclastogenesis (10). This finding supports the contention that the effect of estrogens on osteoclast development may be, in part, secondary to the regulation of CFU-OB self-renewal. In other words, a decrease in the number of cells that support osteoclast development, together with decreased production of osteoclastogenic cytokines by these same cells (7-9), may be responsible for the potent suppression of osteoclastogenesis by estrogens.

In summary, the results of the studies presented here suggest strongly that the increased osteoblastogenesis, bone formation, and perhaps remodeling after loss of estrogens results from the loss of a suppressive effect of these hormones on the self-renewal of CFU-OBs - a transit-amplifying population of osteoblast progenitors in the bone marrow. Future studies will be needed to determine whether this effect is mediated via transcriptional or nongenotropic actions of the ER.

\section{Acknowledgments}

The authors thank Gerard Karsenty and Patricia Ducy for providing OG2- $\beta$-gal founder mice to establish our 
breeding colony and Ken Korach for $E R \alpha^{-/+}$breeders. We also thank Stavroula Kousteni and Oscar Sierra for providing the marrow cells from ovariectomized mice and Catherine O'Brien for technical assistance. This work was supported by NIH grants P01 AG-13918 (to S.C. Manolagas) and F32 AR-08540 (to G.B. DiGregorio) and by the Department of Veterans Affairs (to R.L. Jilka and S.C. Manolagas).

1. Cosman, F., Dempster, D., and Lindsay, R. 1997. Clinical effects of estrogens and antiestrogens on the skeleton and skeletal metabolism. In Estrogens and antiestrogens. R. Lindsay, D.W. Dempster, and V.C. Jordan, editors. Lippincott-Raven Publishers. Philadelphia, Pennsylvania, USA. 151-164.

2. Parfitt, A.M. 1994. Osteonal and hemi-osteonal remodeling: the spatial and temporal framework for signal traffic in adult human bone. J. Cell. Biochem. 55:273-286.

3. Parfitt, A.M., et al. 1983. Relationships between surface, volume and thickness of iliac trabecular bone in aging and in osteoporosis. Implications for the microanatomic and cellular mechanism of bone loss. J. Clin. Invest. 72:1396-1409.

4. Eriksen, E.F., et al. 1990. Cancellous bone remodeling in type I (postmenopausal) osteoporosis: quantitative assessment of rates of formation, resorption, and bone loss at tissue and cellular levels. J. Bone Miner. Res. 5:311-319

5. Poli, V., et al. 1994. Interleukin-6 deficient mice are protected from bone loss caused by estrogen depletion. EMBOJ. 13:1189-1196.

6. Jilka, R.L., et al. 1998. Loss of estrogen upregulates osteoblastogenesis in the murine bone marrow: evidence for autonomy from factors released during bone resorption. J. Clin. Invest. 101:1942-1950.

7. Manolagas, S.C. 2000. Birth and death of bone cells: basic regulatory mechanisms and implications for the pathogenesis and treatment of osteoporosis. Endocr. Rev. 21:115-137.

8. Jilka, R.L. 1998. Cytokines, bone remodeling, and estrogen deficiency: a 1998 update. Bone. 23:75-81.

9. Pacifici, R. 1998. Cytokines, estrogen, and postmenopausal osteoporosis: the second decade. Endocrinology. 139:2659-2661.

10. Jilka, R.L., Weinstein, R.S., Takahashi, K., Parfitt, A.M., and Manolagas, S.C. 1996. Linkage of decreased bone mass with impaired osteoblastogenesis in a murine model of accelerated senescence. J. Clin. Invest. 97:1732-1740.

11. Weinstein, R.S., Jilka, R.L., Parfitt, A.M., and Manolagas, S.C. 1997. The effects of androgen deficiency on murine bone remodeling and bone mineral density are mediated via cells of the osteoblastic lineage. Endocrinology. 138:4013-4021.

12. Potten, C.S., Booth, C., and Pritchard, D.M. 1997. The intestinal epithelial stem cell: the mucosal governor. Int. J. Exp. Pathol. 78:219-243.

13. Pellegrini, G., et al. 1999. Location and clonal analysis of stem cells and their differentiated progeny in the human ocular surface. J. Cell Biol. 145:769-782.

14. Miller, S.J., Lavker, R.M., and Sun, T.T. 1997. Keratinocyte stem cells of cornea, skin and hair follicles. In Stem cells. C.S. Potten, editor. Academic Press. San Diego, California, USA. 331-362.

15. Orkin, S.H. 1996. Development of the hematopoietic system. Curr. Opin. Genet. Dev. 6:597-602.

16. Loeffler, M., and Potten, C.S. 1997. Stem cells and cellular pedigrees: a conceptual introduction. In Stem cells. C.S. Potten, editor. Academic Press. San Diego, California, USA. 1-27.

17. Morrison, S.J., Shah, N.M., and Anderson, D.J. 1997. Regulatory mechanisms in stem cell biology. Cell. 88:287-298.

18. Owen, M. 1988. Marrow stromal stem cells. J. Cell Sci. Suppl. 10:63-76.

19. Aubin, J.E. 1998. Bone stem cells. J. Cell. Biochem. Suppl. 30/31:73-82.

20. Bianco, P., and Gehron, R.P. 2000. Marrow stromal stem cells. J. Clin. Invest. 105:1663-1668.

21. Triffitt, J.T. 1996. The stem cell of the osteoblast. In Principles of bone biology. J.P. Bilezikian, L.G. Raisz, and G.A. Rodan, editors. Academic Press. San Diego, California, USA. 39-50.

22. Beresford, J.N., Graves, S.E., and Smoothy, C.A. 1993. Formation of mineralized nodules by bone derived cells in vitro: a model of bone formation. $\mathrm{Am}$. J. Med. Genet. 45:163-178.

23. Kuznetsov, S.A., et al. 1997. Single-colony derived strains of human marrow stromal fibroblasts form bone after transplantation in vivo. J. Bone Miner. Res. 12:1335-1347.

24. Zou, A., et al. 1999. Estrogen receptor beta activates the human retinoic acid receptor alpha-1 promoter in response to tamoxifen and other estrogen receptor antagonists, but not in response to estrogen. Mol. Endocrinol. 13:418-430.

25. Frendo, J.L., et al. 1998. Functional hierarchy between two OSE2 elements in the control of osteocalcin gene expression in vivo. J. Biol. Chem. 273:30509-30516.

26. Couse, J.F., et al. 1995. Analysis of transcription and estrogen insensitivity in the female mouse after targeted disruption of the estrogen receptor gene. Mol. Endocrinol. 9:1441-1454.

27. Dobson, K.R., Reading, L., Haberey, M., Marine, X., and Scutt, A. 1999. Centrifugal isolation of bone marrow from bone: an improved method for the recovery and quantitation of bone marrow osteoprogenitor cells from rat tibiae and femurae. Calcif. Tissue Int. 65:411-413.

28. Kuznetsov, S., and Robey, P.G. 1996. Species differences in growth requirements for bone marrow stromal fibroblast colony formation in vitro. Calcif. Tissue Int. 59:265-270.

29. Klein, C.E., et al. 1991. Integrin alpha 2 beta 1 is upregulated in fibroblasts and highly aggressive melanoma cells in three-dimensional collagen lattices and mediates the reorganization of collagen I fibrils. J. Cell Biol. 115:1427-1436

30. Stenoien, D.L., et al. 2000. Subnuclear trafficking of estrogen receptor-alpha and steroid receptor coactivator-1. Mol. Endocrinol. 14:518-534.

31. Littell, R.C., Milliken, G.A., Stroup, W.W., and Wolfinger, R.D. 1996. SAS system for mixed models. SAS Institute. Cary, North Carolina, USA. 87-134.

32. Glowacki, J., Mizuno, S., and Greenberger, J.S. 1998. Perfusion enhances functions of bone marrow stromal cells in three-dimensional culture. Cell Transplant. 7:319-326.

33. Wang, T.-Y., Brennan, J.K., and Wu, J.H.D. 1995. Multilineal hematopoiesis in a three-dimensional murine long-term bone marrow culture. Exp. Hema tol. 23:26-32.

34. Pockwinse, S.M., et al. 1993. Gene expression at single cell resolution associated with development of the bone cell phenotype: ultrastructural and in situ hybridization analysis. Bone. 14:347-352.

35. Liu, F., Malaval, L., Gupta, A.K., and Aubin, J.E. 1994. Simultaneous detection of multiple bone-related mRNAs and protein expression during osteoblast differentiation: polymerase chain reaction and immunocytochemical studies at the single cell level. Dev. Biol. 166:220-234.

36. Liao, D.Z., Pantazis, C.G., Hou, X., and Li, S.A. 1998. Promotion of estrogeninduced mammary gland carcinogenesis by androgen in the male Noble rat: probable mediation by steroid receptors. Carcinogenesis. 19:2173-2180.

37. Parfitt, A.M. 1996. Skeletal heterogeneity and the purposes of bone remodeling. In Osteoporosis. R.Marcus, D. Feldman, and J. Kelsey, editors. Academic Press Inc.. San Diego, California, USA. 315-329.

38. Parfitt, A.M. 1990. Bone-forming cells in clinical conditions. In Bone. Volume 1: the osteoblast and osteocyte. B.K. Hall, editor. Telford Press and CRC Press. Boca Raton, Florida, USA. 351-429.

39. Jilka, R.L., et al. 1992. Increased osteoclast development after estrogen loss: mediation by interleukin-6. Science. 257:88-91.

40. Falla, N., et al. 1993. Characterization of a 5-fluorouracil-enriched osteoprogenitor population of the murine bone marrow. Blood. 82:3580-3591.

41. McCulloch, C.A., Strugurescu, M., Hughes, F., Melcher, A.H., and Aubin, J.E. 1991. Osteogenic progenitor cells in rat bone marrow stromal populations exhibit self-renewal in culture. Blood. 77:1906-1911.

42. Lehrer, M.S., Sun, T.T., and Lavker, R.M. 1998. Strategies of epithelial repair: modulation of stem cell and transit amplifying cell proliferation. J. Cell Sci. 111:2867-2875.

43. Potten, C.S. 1998. Stem cells in gastrointestinal epithelium: numbers, characteristics and death. Philos. Trans. R. Soc. Lond. B Biol. Sci. 353:821-830.

44. Chanda, S., Robinette, C.L., Couse, J.F., and Smart, R.C. 2000. 17beta-estradiol and ICI-182780 regulate the hair follicle cycle in mice through an estrogen receptor-alpha pathway. Am. J. Physiol Endocrinol. Metab. 278:E202-E210.

45. Clarke, C.H., et al. 2000. Perimembrane localization of the estrogen receptor alpha protein in neuronal processes of cultured hippocampal neurons. Neuroendocrinology. 71:34-42.

46. Shim, W.S., et al. 1999. Segregation of steroid receptor coactivator-1 from steroid receptors in mammary epithelium. Proc. Natl. Acad. Sci. USA. 96:208-213.

47. Saji, S., et al. 2000. Estrogen receptors alpha and beta in the rodent mammary gland. Proc. Natl. Acad. Sci. USA. 97:337-342.

48. Kousteni, S., et al. 2001. Non-genotropic, sex non-specific signaling through the estrogen or androgen receptors: dissociation from transcriptional activity. Cell. 104:719-730.

49. Li, H., et al. 2000. Cytochrome c release and apoptosis induced by mitochondrial targeting of nuclear orphan receptor TR3. Science. 289:1159-1164.

50. Simoncini, T., et al. 2000. Interaction of oestrogen receptor with the regulatory subunit of phosphatidylinositol-3-OH kinase. Nature. 407:538-541.

51. Mbalaviele, G., et al. 1999. Human mesenchymal stem cells promote human osteoclast differentiation from $\mathrm{CD}_{3} 4^{+}$bone marrow hematopoietic progenitors. Endocrinology. 140:3736-3743.

52. Taylor, L.M., Turksen, K., Aubin, J.E., and Heersche, J.N.M. 1993. Osteoclast differentiation in cocultures of a clonal chondrogenic cell line and mouse bone marrow cells. Endocrinology. 133:2292-2300. 